$\frac{269}{11-139}$ A-7885-MS, Vol. V Informal Report

$D R .277$

\title{
MASTE?
}

\section{1-GWh Diurnal Load-Leveling Superconducting Magnetic Energy Storage System Reference Design} Appendix D: Superconductive Magnetic Energy Storage Cavern Construction Methods and Costs

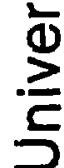

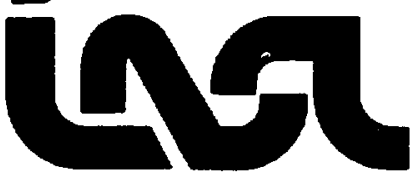


LA-7885-MS, Vol. V Informal Report UC-20b and UC-94b

Issued: September 1979

\section{1-GWh Diurnal Load-Leveling Superconducting Magnetic Energy Storage System Reference Design Appendix D: Superconductive Magnetic Energy Storage Cavern Construction Methods and Costs}

Fenix \& Scisson, Inc. *

${ }^{*}$ Fenix \& Scisson, incorporated, Tulsa, OK 74000. 


\title{
MASTER
}

1-GWh DIURNAL LOAD-LEVELING SUPERCONDUCTING MAGNETIC ENERGY STORAGE SYSTEM REFERENCE DESIGN

APPENDIX D

SUPERCONDUCTIVE MAGNETIC ENERGY STORAGE

CAVERN CONSTRUCTION METHODS ANO COSTS

by

Fenix \& Scisson, Inc.

\begin{abstract}
The excavation and preparation of an underground cavern to contain a 1-GWh diurnal load-leveling Superconducting Magnetic Energy Storage (SMES) unit is examined. The cavern's principal function is to provide a rock structure for supporting the magnetic forces from the charged storage coil. Certain economic considerations indicate the refrigerator cold box for the helium system should also be underground. The study includes such a provision and considers, among other things, rock bolting, water seepage, concrete lining of the walls, steel bearing pads, a system to prevent freezing of the walls, a mining schedule, and costs.
\end{abstract}

I. INTRODUCTION

Construction of the Superconductive Magnetic Energy Storage (SMES) cavern can be accomplished using conventional mining equipment and established mining methods. See Fig. D-1. Depending on the proposed location, conditions may vary widely with respect to the water table and neneral rock characteristics. Because of these variables, the cost of the structure will differ accordingly. Preliminary core drilling will provide a pattern of underground rock features and water bearing zones, but only actual construction will bring to light the exact nature of the rock and associated mining problems. 
In the ensuing report, a generalized description of each phase of the project is included together with a series of conceptual illustrations. The project is divided into specific tasks, and costs are provided for each task based on cavern depths of 500,300 , and $200 \mathrm{~m}$. A proposed construction schedule is provided based on a cavern depth of $500 \mathrm{~m}$. Interestingly, if the alternative depths of $300 \mathrm{~m}$ or $200 \mathrm{~m}$ were selected, the construction schedule would not be appreciably shortened. The expense and time consuming construction lies in the upper and lower tunnels and the interconnecting slot. This structure, when completed, will be waterproof and formed to support the $3.09 \times 10^{6} \mathrm{~kg}$ axial load. Although Fenix and Scisson, Inc. (F\&S) has designed the slot to be fully concrete lined with vertical walls, some future modification of the lining and its surface may be desirable as the support system approaches final design. The slot concrete lining can be formed for support surfaces at virtually any angle desired.

Construction of the cavern was assumed for this report to be in a homogeneous rock with a minimum compressive strength of $703 \mathrm{~kg} / \mathrm{cm}^{2}$. Water will permeate through a number of joints or fractures within the rock at a maximum static head pressure of $54 \mathrm{~kg} / \mathrm{cm}^{2}$. The water can be sealed off during tunnel construction by pressure grouting ahead of the advancing face whenever it is encountered during standard drilling for blast rounds. Undoubtedly, one of the criteria for site selection will be a minimum amount of water or a low static pressure head which will lessen many of the construction problems.

\section{SCOPE}

The scope of this cost estimate consists of the underground construction required for placement of superconducting magnetic coils and their associated service machinery. This estimate includes the cost of construction, several vertical shafts using both drilled and conventional construction techniques. Construction will consist of circling tunnels, dewar slot, and an associated equipment room. The entire excavated facility will be either stabilized with rock bolts and wire mesh or concrete lined depending upon the use anticipated for a particular area. The estimate does not include installation of the coil and the associated equipment. 


\section{SURFACE CONSTRUCTION}

Following approval of design and specifications for the SMES cavern, surface facilities will be constructed to handle crews, machinery, materials, and excavated rock. See Fig. 0-2. After a detailed survey, roads will be constructed to connect the shaft area with drill pad locations. Electric power will be brought to the property and terminated at a transformer station for future rcuting. Compressors will be installed and housed to supply machine air requirements and buildings constructed for shop and warehouse areas, changeroom and shower facilities, and field headquarters. Storage tanks for fuel, oil, and gasoline will be installed. A fresh-water supply and sanitary facilities will be obtained. A perimeter security fence will be erected around the construction site.

\section{DRILLING}

Six 1.82-m-diam holes will be drilled to the eventual depth of the upper level tunnel and lined with $1.37-m-d i a m ~ s t e e l$ casings grouted into place. Auxillary compressed air and water lines can be slipped down the annulus of the casing, then grouted into place. Then a 1.2-m diam drill bit will be slipped through the casing and the hole continued to the proposed depth of the lower level tunnel.

Each of the six holes will be drilled and cased alike. Two drill rigs will be utilized to complete the holes within a prescribed time frame. The first hole to be drilled will be the one nearest the production shaft with subsequent drilling advancing away from the shaft. After a hole is completed, a $1.37-m$ diam exhaust fan will be installed at the collar to increase air circula: ion in the tunnels. Expected time required for drilling and casing the six holes is approximately 2 yrs.

\section{v. PROUUCTION SHAFT}

The main production shaft will be a three-compartment, 3.96- by 3.35-m shaft. Two compartments, $1.85-\mathrm{m}$ square each, will be used for balanced muck. hoisting while the third compartment will be for a manway and will contain air, water, and ventilation lines. See Fig. D-3. The shaft will be concrete lined from the surface to the bottom of the sump for maximum stability.

Shaft construction will begin on the surface with the installation of an 80-ton steel headframe, a double-drum hoist, and a 15-m concrete collar that 
follows excavation. Then a multideck sinking platform will be lowered into the collar. The platform will be capable of handling the movement of forms and placement of concrete while mucking is being carried out below. The lower deck of the platform will be equipped with a portable four-boom jumbo and a $0.5-\mathrm{m}^{3}$ clamshell bucket. Bucket wells in the platform will allow for mucking out the shaft bottom.

The shaft will be deepened at a rate of $3 \mathrm{~m}$ per 24-h period. Following the drill cycle, the holes will be loaded with explosives and the platform raised a minimum of $45 \mathrm{~m}$. The explosives will then be detonated. After allowing sufficient smoke-clearing time, the platform will be lowered into place and mucking will proceed. Simultaneously, 2-m-high concrete jump iorms will be attached to the shaft wall for the lining operation. Concrete will be de]ivered simultaneously from the surface through a $15-\mathrm{cm}$ slick ine to a remix pot, where it will be distributed to the forms on the shaft perimeter.

F\&S has assumed that ground conditions will allow for lining of the shaft some distance above the excavation, with simultaneous operations being performed. Unstable or wet ground may require that the lining be installed much closer to the bottom and placed in shorter lifts. The equipment described above is readily adapted to this situation but will require the elimination of simultaneous operation, either in part or entirely.

Where water inflows are encountered in quantities affecting sinking progress, grouting may become necessary when pumping or bailing proves insufficient.

In contrast to a shaft sunk by conventional methods, a drilled shaft may be more desirable. Present technology and equipment have not advanced at this time to drill a hole of comparable area to the depths desired. However, much work is currently being done in this area, and the capability may exist within the next few years.

\section{TUNNEL CONSTRUCTION}

During the shaft sinking project, landings will be excavated at each of the two designated tunnel elevations. Once the shaft is complete and equipped for balanced production hoisting, small mining equipment consisting of handheld drills and air-powered mucking machines will be lowered to each level. A cavity will be excavated large enough for assembly of the diesel-powered loaders, jumbo-drill rigs, and skip-loading stations. 
On each of the two levels, initial efforts will be directed toward intercepting the nearest $1.37-\mathrm{m}-\mathrm{diam}$ cased hole to provide air circulation, then the headings will be turned to a circular arc direction to intercept each of the five remaining drilled holes. Because alignment of these tunnels is a critical requisite to the overall cavern specifications, surveys will be performed daily to insure that the upper and lower tunnels are concentric and aligned vertically.

While a face is being drilled, holes will be added for pattern rockbolting along 1.5-min centers. After the round is blasted, loose rock will be scaled and rockbolts installed. Where heavy fracturing or unstable ground is encountered, wire mesh will be installed for additional support. A wet-mix shotcrete layer then will be applied to the exposed rock surfaces of the tunnels to optimize long-term tunnel stability. Pressure grouting will be performed where necessary to prevent water flow into the tunnels.

The upper and lower 5- by 6-m circling tunnels will advance at a rate of $7.3 \mathrm{~m}$ per 24-h period. The drill jumbos will work in one end of the arc while bolting and mucking are in progress on the ather end of the arc. Thus, each tumel leve? will advance on two headings.

Concurrent with the tunnel construction, an additional tunnel will be ariven from the lower level shaft landing a distance of $175 \mathrm{~m}$ on a radial extending outward from the axis of the circling tunnels to locate and provide access to the equipment room and equipment shaft. See Fig. 0-4. Standard rockbolts will be installed on 1.5-m centers with wire mesh where necessary.

\section{SLOT CONSTRUCTION}

The most dificult and expensive miring phase anticipated will be the construction of the circular slot connecting the upper and lower level tunnels. See Fig. ' $0-5$. The difficulty of mining lies in the slot's shape, $44 \mathrm{~m}$ high and $3 \mathrm{~m}$ wide on a circular length of $415 \mathrm{~m}$. The expense lies in its design requirements: impermeable, vertical concrete walls with a minimum compressive strength of 422 to $563 \mathrm{~kg} / \mathrm{cm}^{2}$, with $25-\mathrm{mm}$-diam copper pipes vertically spaced on $1-m$ centers and formed in the center of the inner and outer concrete walls for the full circumference of the slot. Both concrete walls will have. 25-mil-thick by 1-m-square steel plates mechanically anchored through the concrete and into the rock by eight $50-m-d i a m$ by $1-m-1$ ong $z$ inc-plated rockbolts 
and placed on prescribed intervals for eventual support of axial and radial loads.

Excavation and construction of the slot will be performed in a three-step operation with each phase being performed in an area independent of the other two.

First, two air-track drills will pattern drill a bench $4 \mathrm{~m}$ wide and $20 \mathrm{~m}$ long on $1.5-\mathrm{m}$ centers to a depth of $2 \mathrm{~m}$. The sides will be line drilled for smooth-wall blasting. After the lift is blasted, small crawler dozers will push the muck down the closest 1.2-m-diam drilled hole to the lower level, where it will be loaded from chutes, hauled to the production shaft, and hoisted to the surface.

Second, loose rock will be scaled, and sheets of 12-gauge galvanized plate will be overlapped and secured to the rock by $15-\mathrm{mm}$ rockbolts. This plate will act as a water barrier and stabilize the sidewalls. All seams will be filled with a special expanding polymer sealant.

The third and final step will be to construct the finished concrete liner. The 25-mm copper pipes will be attached to existing pipes in place on $1-m$ centers and suspended vertically below the eventual $2-m$ depth of the next pour.

Portable jump forms will be placed and concrete pumped into the forms under pressure from a remix plant on the upper level. Both the inside and outside walls of the lift will be built concurrently with hydraulic jacks applying horizontal pressure. After the walls are set sufficiently, the forms will be contracted and transported by section into place for the next pour. Each of the 1-m-square by $25-\mathrm{mm}-$ thick steel plates will be anchored by eight 50-m diam by $1.5-m$ solid-steel, zinc-plated rockbolts.

Construction of the slot will begin at the upper tunnel; and when completed, all equipment will be removed through the lower tunnel. A special drainage system will be installed at the lower level to transport collected water to the shaft sump for puming to the surface.

\section{EQUIPMENT SHAFT CONSTRUCTION}

The equipment shaft will be located directly over the equipment room, approximately $270 \mathrm{~m}$ horizontally from the axis of the circular tunnels. See Fig. D-4. As a single compartment structure, its finished inside dimensions 
will be $3.9 \mathrm{~m}$ square. The shaft will be lined with concrete for its full depth.

This shaft will be constructed as a raise with the access drift being used for entry. An electrically driven monorail-guided Alimak raise climber will be installed for construction. Initially, the raise will be driven $2.5 \mathrm{~m}$ square to the height of the shaft. After surface penetration, the shaft will be enlarged to its full $4.7-\mathrm{m}$ width by using a type $R$ shaft enlarging platform. This platform is equipped with controls for raising and lowering the platform and four telescoping drill machines. In both raising and enlarging instances, the blasted rock will fall to the bottom of the shaft where it will be loaded and hauled through the access tunnel to the production shaft for hoisting to the surface. Slip forms will be fitted at the bottom of the shaft, and a concrete lining will be poured from the bottom to the top of the shaft.

\section{EQUIPMENT ROOM}

The equipment room will be located at the end of the access drift connecting it with the production shaft and will be at the bottom of the equipment shaft. See Fig. D-4. This room will be excavated to house special pumps and will be $20 \mathrm{~m}$ by $20 \mathrm{~m}$ wide by $10 \mathrm{~m}$ high.

Although this room is quite large, no special support problems are anticipated. Complete roof and sidewall support will include pattern bolting on 1.5-m centers over heavy mesh covering. Cables with mechanical anchors couid be used in part, or wholly, and interwoven with the wire mesh for additional support. If conditions warrant, structural concrete pillars may also be constructed.

Mining will be by conventional methods with the primary concern of outlining the roof, supporting it, and benching down to floor elevation. Construction time for this equipment room should be 8 to 1.2 wh.

The construction costs for the cavern are summarized by depth of the cavern in Table D-I. 
TABLE D-I

CONSTRUCTION COST SUMMARY FOR SMES CAVEPN BY DEPTH OF CAVERN

\begin{tabular}{|c|c|c|c|}
\hline Tasks & 200 Meters, $\$$ & 300 Meters, $\$$ & 500 Meters, $\$$ \\
\hline Surface construction & 530430 & $\begin{array}{lll}530 & 430\end{array}$ & 530430 \\
\hline $\begin{array}{l}\text { Drilling and casing } \\
6,1.37-m \text { holes }\end{array}$ & 8017062 & 9440964 & 13138988 \\
\hline $\begin{array}{l}\text { Sink and line production } \\
\text { shaft }\end{array}$ & 2428444 & 2851042 & 3695238 \\
\hline Excavate tunnels & 4915113 & 4915113 & 4915113 \\
\hline Excavate and construct slot & 17731526 & 17731526 & 17731526 \\
\hline $\begin{array}{l}\text { Raise and line equipment } \\
\text { shaft }\end{array}$ & 519676 & 779515 & 1299192 \\
\hline Excavate equipmerit room & 76000 & 76000 & 76000 \\
\hline Expendab les & 1157800 & 1157800 & 1157800 \\
\hline Indirect 1 abor & 947260 & 947260 & 947260 \\
\hline Indirect expenses & 152000 & 152000 & 152000 \\
\hline $\begin{array}{l}\text { General and administration } \\
\text { costs }\end{array}$ & 984833 & 1041704 & 1178375 \\
\hline Sales tax & $70818 ?$ & 813499 & 1216594 \\
\hline Construction insurance & 241528 & 255763 & 291193 \\
\hline Contingencies & 3816832 & 4043685 & 4603851 \\
\hline $\begin{array}{l}\text { Engineering and } \\
\text { construction fee }\end{array}$ & 6320573 & 6673080 & 7596355 \\
\hline TOTALS & $\$ 48 \quad 547 \quad 259$ & $\begin{array}{lll}\$ 51 & 409 & 381\end{array}$ & $\$ 58 \quad 529 \quad 915$ \\
\hline
\end{tabular}




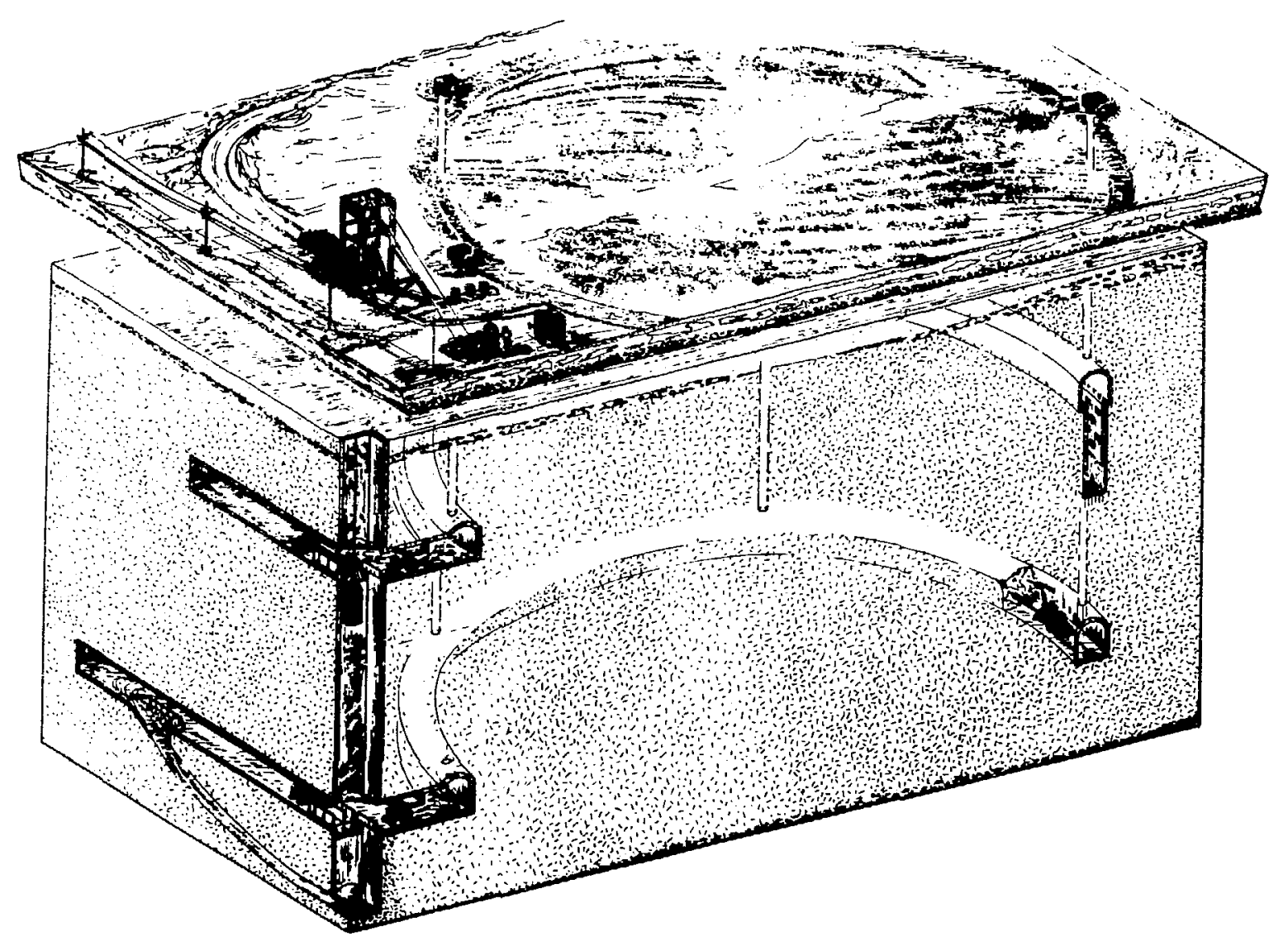

rig. D-1.

Concept of a superconducting magnetic energy storage cavern. 


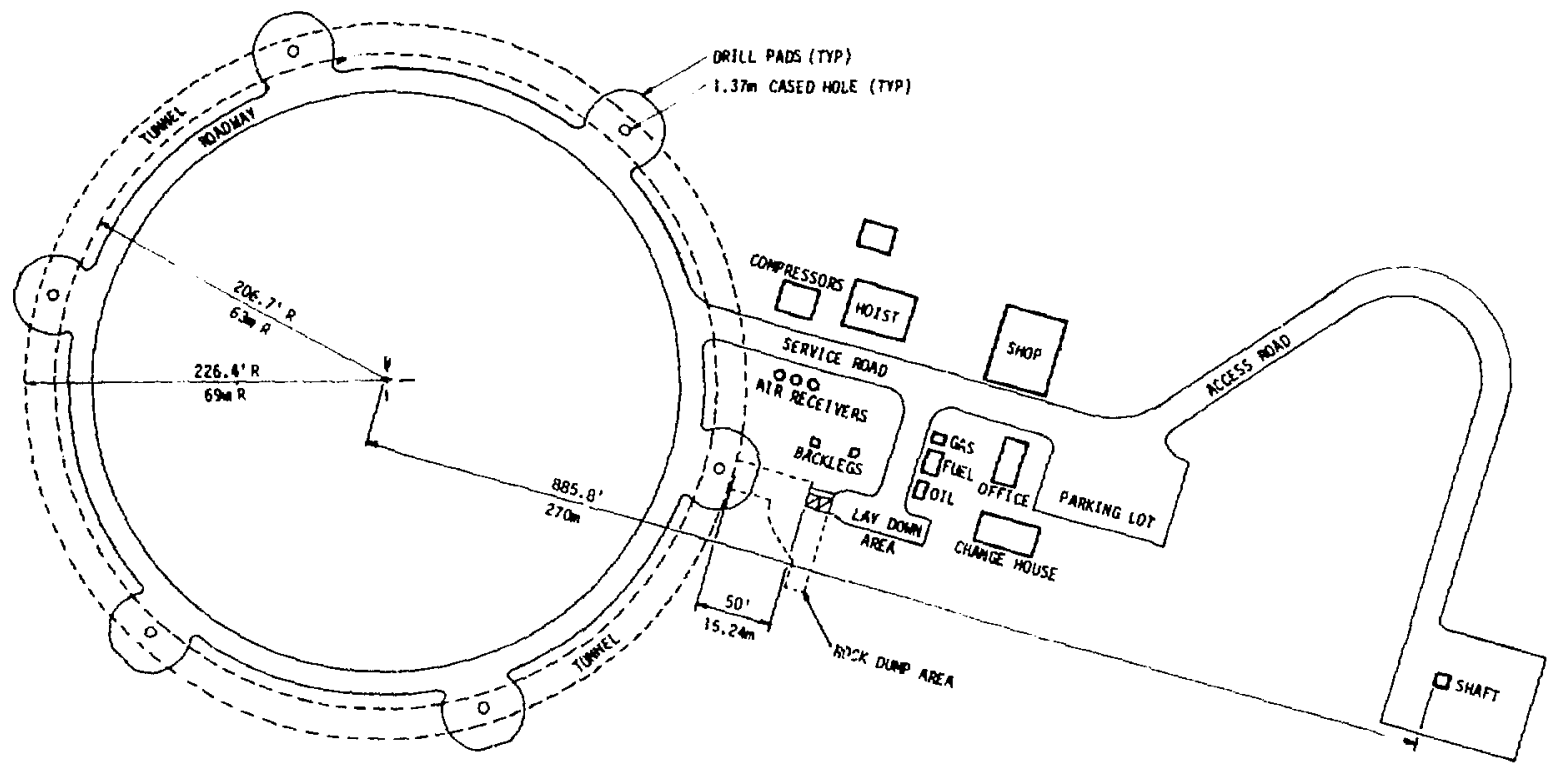

Fig. $0-2$.

SMES surface layout.
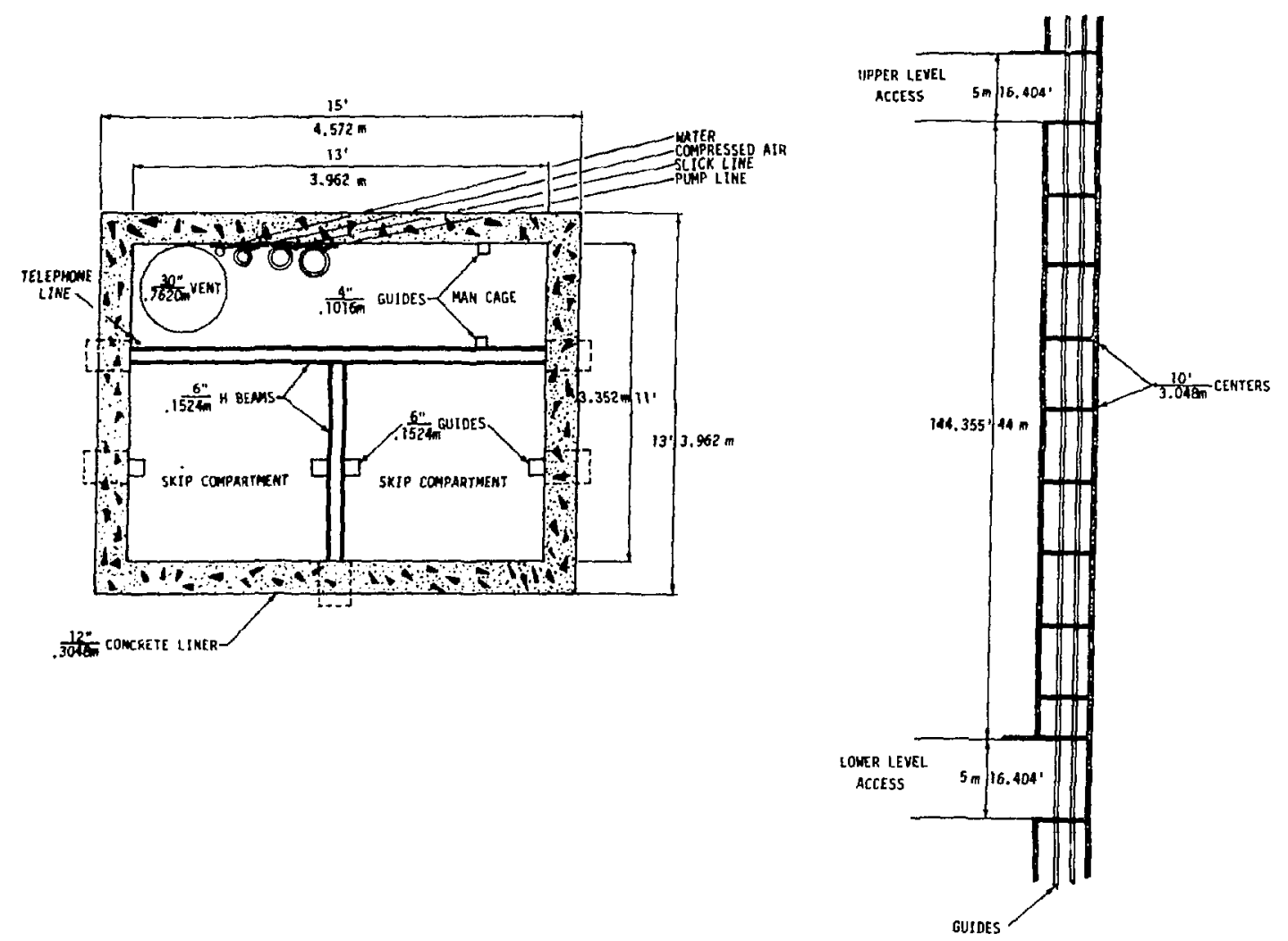

Fig. 0-3.

Production shaft design. 


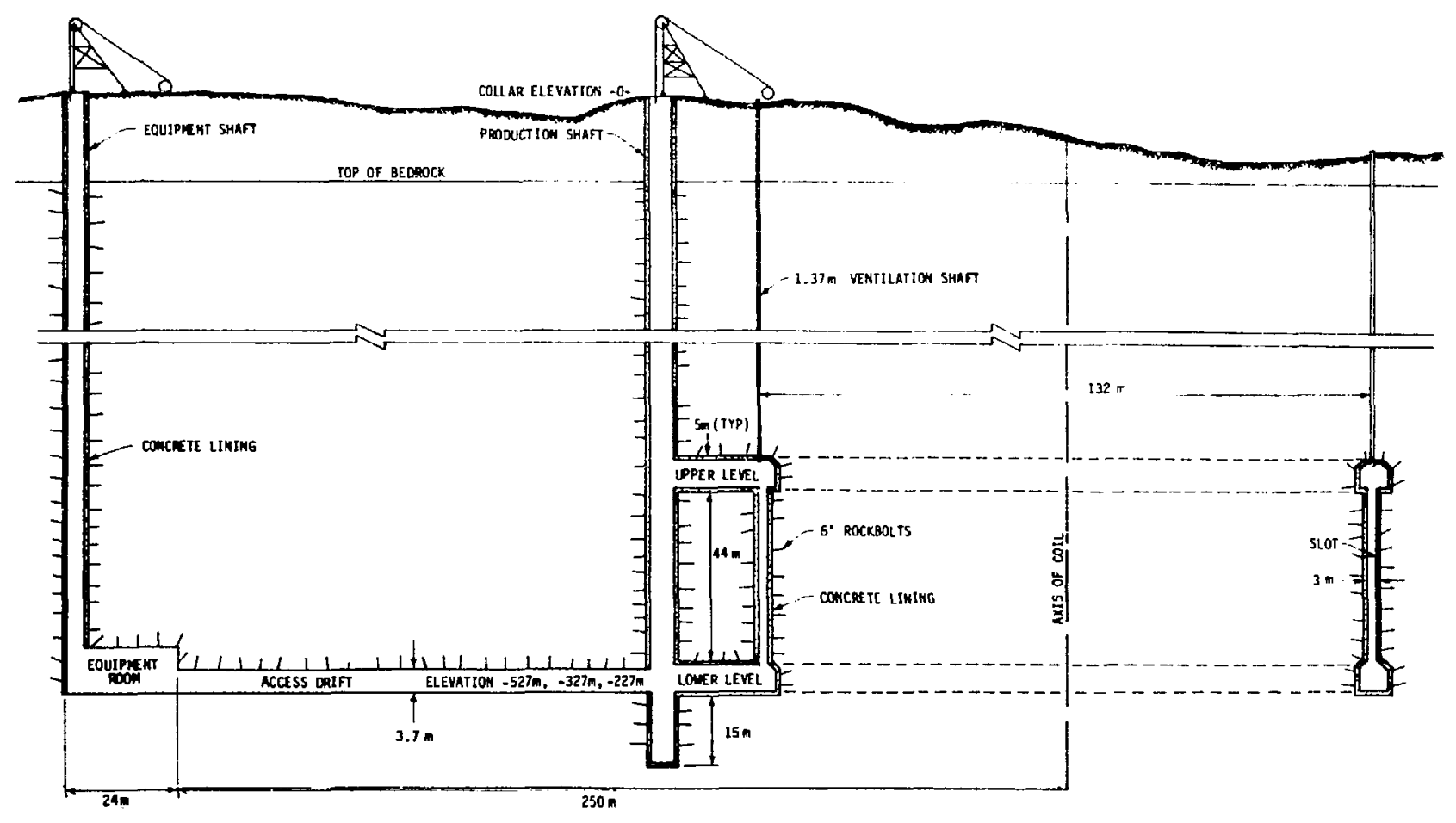

Fig. D-4.

Schematic cross section of proposed SMES cavern. 


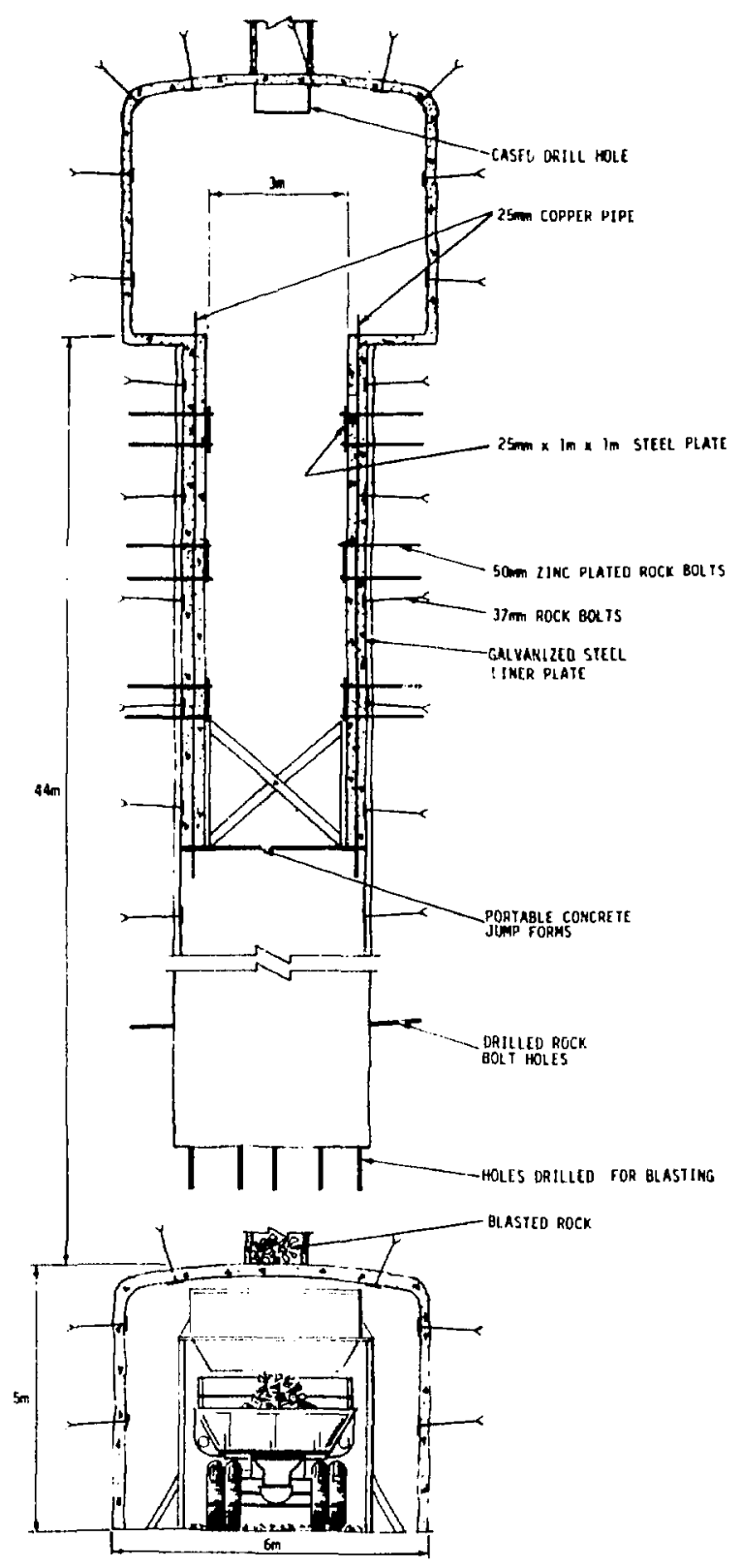

Fig. D-5.

SMES slot construction. 


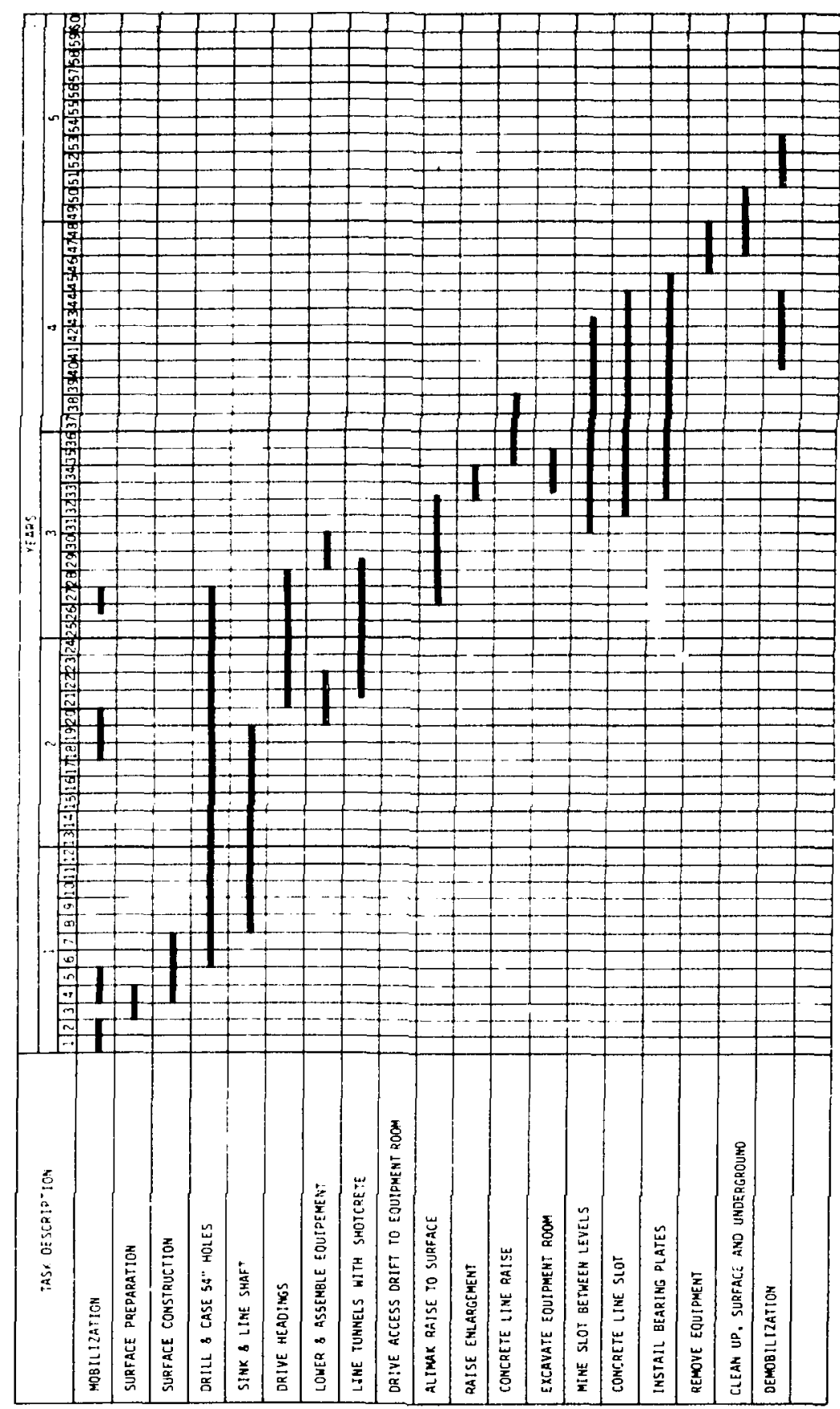

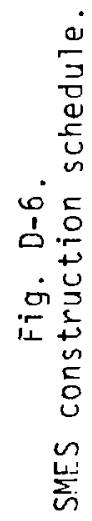

